This item was submitted to Loughborough's Research Repository by the author.

Items in Figshare are protected by copyright, with all rights reserved, unless otherwise indicated.

\title{
Sustainable supply chain finance and supply networks: The role of artificial intelligence
}

\section{PLEASE CITE THE PUBLISHED VERSION}

https://doi.org/10.1109/tem.2021.3133104

\section{PUBLISHER}

Institute of Electrical and Electronics Engineers (IEEE)

VERSION

AM (Accepted Manuscript)

\section{PUBLISHER STATEMENT}

Personal use of this material is permitted. Permission from IEEE must be obtained for all other uses, in any current or future media, including reprinting/republishing this material for advertising or promotional purposes, creating new collective works, for resale or redistribution to servers or lists, or reuse of any copyrighted component of this work in other works.

\section{LICENCE}

\section{All Rights Reserved}

\section{REPOSITORY RECORD}

Olan, Femi, Emmanuel Ogiemwonyi Arakpogun, Uchitha Jayawickrama, Jana Suklan, and Shaofeng Liu. 2022. "Sustainable Supply Chain Finance and Supply Networks: The Role of Artificial Intelligence". Loughborough University. https://hdl.handle.net/2134/17929241.v1. 
Sustainable Supply Chain Finance and Supply Networks: The role of Artificial Intelligence 


\title{
Sustainable Supply Chain Finance and Supply Networks: The role of Artificial Intelligence
}

\begin{abstract}
Supply Chain Finance (SCF) is receiving increasing awareness in research as a result of uncertainties in the global financing for supply chain (SC). There are limited and fragmented studies in the implementations of financial services in supply chain management. This study builds on recovery from the financial crisis of 2008 and posts COVID-19 pandemic, where uncertainties crippled SCF providers and brokers services. At the same time, cutting-edge technological advancements such as artificial intelligence (AI) are revolutionizing the processes of business ecosystem in which SCF is entrenched. This study thus adopts a fuzzy set theoretical approach to unpack the entities relationship validity for sustainable SCF mate-framework, and the originality of AI concepts to sustainable SCF to identify the issues and inefficiencies. The results indicate that AI contributes significant economic opportunities and deliver the most effective utilization of the supply networks. In addition, the study provides a theoretical contribution to financing in SC and broadens the managerial implications in improving performance.
\end{abstract}

Keywords supply chain finance, supply chain network, artificial intelligence, supply chain 


\section{Introduction}

In the last two decades, technological advancements in supply chain (SC), underpinned by Computerized Shipping and Tracking (CST), Enterprise Resource Planning (ERP) and Big Data, are still emerging with innovations contributing not only to human intelligence, data analytics, and system thinking but efficiency of supply chain management. In particular, the potentials of supply chain networks as assets for supply chain companies, combining technologies and systems applications to the SC modules. However, the application of artificial intelligence (AI) technologies in SC is rather too slow or limited while the distribution of enterprise environments is at a higher stage of implementation in their operations [1]. Conventionally, supply chain finance (SCF) focuses mainly on financial aspects of supply chain management, particularly defining inventories as cash flows in view of an application for financial services in this sector of global business [2]. Furthermore, AI is one of the enablers of global financing in business services, hence the role of AI in building a relationship between SCF and supply chain networks [3-5]. The introduction of AI technologies, according to Du, et al. [6] primarily reduces SCF and SCN challenges such as lack of consideration of operations assets available in supply networks during application for financing limits the capacity of SCN. Nevertheless, with the emerging opportunities through AI-enabled SCN, sustainable financial services can be implemented $[4,7-10]$ Thus, SC operations exist in multiple environments categorized by technology, organizational culture, and systems that vary depending on the policies in the region where they operate [11]. Therefore, in terms of major challenges that exist in the SCF and supply chain networks environments such as increasing regulations imposed by financial providers, AI can provide pathways to overcome these barriers by analyzing information and data flow and providing alternatives in SC operations. In addition, SCF has become the hub for processing global supply chain financial services in this age of digital transformation. Global markets and 
supply chain operations now face the challenges of developing innovations and technologies to integrate supply chain networks with financial services.

Past SCF studies have examined the impact of the last economic recession on financing in SC, they proposed inter-organizational management of financial flows and the advantages of infrastructure sharing as working models for SC [12, 13]. Most of the previous work focused on inter-organizational SCF however supply chain networks and technological advancements such as AI have very limited considerations, as supply chain networks continue to grow, leveraging technology-driven financing methods such as procure-to-pay, which integrate both financing functionalities and purchase management systems are becoming prefer alternatives for SC financing [14]. Furthermore, large financial brokers and institutions are supporting these emerging initiatives worldwide, AI systems from current studies are projected as the tool to advance the course of financing in the supply chain management post COVID-19 pandemic, offering more reliable partnerships between the financier and the supply chain companies [15]. Furthermore, supply chain networks act as a single colossal system of interconnecting supply chain companies and financial institutions/brokers, providing a link to control and manage financial services, tracking, and cash flows. Nevertheless, gaining continuous access to the supplier's networks requires direct relationships with companies' operations, and a higher level of SC integrations, which also has a direct impact on the independence of an individual supplier's security. The role of AI as a technological tool is to bridge and stimulate SC financing through existing supply chain networks, minimizing complications experienced by valuable supply chain companies as a result of tougher financing application requirements, understanding the designs and operations of supply chain networks $[4,5,16,17]$. Thus, this study investigates the theoretical research on SCF, supply chain networks, and AI in supply chain management, which leads to two primary research questions: 
$R Q 1$. What are the components of SCF and supply chain networks that are required for an AI system?

$R Q 2$. Can AI simplify SC financing by understanding the relationship between SCF and supply chain networks?

To achieve the objectives in this study, a fuzzy set theoretical approach for complimentary and equifinality of entities relationship as proposed in the conceptual metaframework because it can evaluate consistency and coverage threshold among the criteria. This research responds to the need for theoretical insights to SC financing and the importance of supply chain networks. This paper first explores the theoretical background, then presents an in-depth study, data analysis, and the findings. Lastly, the paper concludes with a discussion of the implications of this paper for research and practice, limitations, and future research directions.

\section{Theoretical Background}

Sustainable SC financing as a continuous process tackles the challenges posed since the 2008 economic recession and post COVID-19 pandemic by holistically connecting financial institutions and brokers with supply chain companies, past studies argued for collaborative resources sharing, financing models and government grants for SC sector. As prior studies examined single factors of SCF risks [18], SCF opportunities [19], and SC firms [7], this section provides an in-depth review of SCF, supply chain networks, and AI with a perspective on a conceptual meta-framework.

\subsection{Sustainable Supply Chain Finance}

According to past studies, there is a common phenomenon in SC that information, products, and financial flows are relevant factors in theories and to practitioners in understanding how to improve financing across supply chain companies [12]. According to Caniato, et al. [20], 
supply chain companies consist of entities that operate in supply chain management which include suppliers, transportations, retailers, etc. Based on this understanding, considerable efforts were devoted to studying product mobility and data flows [21]. However, this does not apply to financial flows, where advanced optimization around product mobility and data flows is not up to date in terms of the integration of supply chain operations and financing. In general, a new stream of literature is emerging on some related topics to bridge this gap in the research.

In this age of digitalization, supply chain companies are facing enormous pressure regarding the operations of their business activities and processes, providing the best service without disruptions and meeting the needs of their customers [22]. The evolving innovation in information technology (IT) provides a new paradigm for SC operations, and some challenges for supply chain companies are becoming manageable [7]. Nevertheless, the recent financial crisis and COVID-19 pandemic led to various difficulties for supply chain companies, customers' demand has skyrocketed with a limited turnaround time, creating the need for supply chain companies to seek more financial resources to meet the ever-growing demand in the market [23]. Tactlessly, with the last financial crisis, financial institutions and brokers raised the standards and requirements for financing applications [12], making it extremely difficult to access financing for companies with inadequate cash flows.

Furthermore, to meet the level of demand, supply chain companies require consistent and stable cash flows for sustainable and efficient daily operations. Carnovale, et al. [24] argued that SCF driven by technology is an innovative method that solves the problems of financing for supply chain companies by considering cash flows and other activities in their operations. In addition, Hugo [18] further explains the principle of SCF as a fundamentally integral component of financing in SC processes, financial institutions and brokers provide some credit and trade financial services to facilitate and support supply chain companies' 
operations, another study [25] argued that SCF as a financing solution for SC provides alternative solutions for credit issues improving supply chain companies performance by working in partnership with other companies and leveraging joint resources to reduce the risks of interruptions while supporting financing and operations opportunities in SCs.

Hence, SC financing can take advantage of the commercial finance environment by combining technological advancement and financial solutions into a single system for financial and operational integration. Osadchiy, et al. [26] argued that SC financing such as business-2-business (B2B) also known as trade credit and crowdfunding, in practical terms, are expanding as their customer networks grow at an exponential rate. Nonetheless, the challenge of cash flow deficiency remains as supply chain companies' financial and operational problems. Hence, exploring technological innovations for SC financing is not just important for research, also SC cash flows as supply chain companies are constantly seeking ventures from multiple sources from the financial capital market and stakeholders to sustain their operations and improve their partnerships [27].

As SCF is the most important financing solution for most supply chain companies that are struggling with access to steady and readily available cash flow, Zhao and Huchzermeier [28] further categorize SCF into collateral SCF, time-based SCF, and credit SCF. According to financial economics theory, supply chain companies have the ability to achieve specific organizational goals and excel when there is a financial mechanism in place to support their goals and objectives [29]. Spyridon and Serrano [25] provided a detailed outline of the role of financial institutions and brokers in granting financial facilities to supply chain companies by managing the information asymmetry in cash flows.

\subsection{Supply Chain Networks}

Supply chain networks represent the new integrative innovation in the SC financing 
processes for SC partnerships working towards a beneficial pool of resources and improving products and services, supply chain companies are investing in innovative processes, as their operations are directly linked with financial services [30]. In supply chain management context, the environment is fundamental for supply chain networks, most especially when supply chain companies inter-link both their associated suppliers and customers [31, 32]. Consequently, the relationships among partners (supply chain companies, suppliers, and customers) in the definition of the overall structure for a sustainable supply chain networks, assuming the significant integration of new structures with existing interconnections. Scholars discussed how supply chain management studies are continuing to improve supply chain networks theory and helping to tackle SC challenges [33].

The need to establish sustainable supply chain networks for SC financing led to the search for more knowledge through research on supply chain networks-based theories and applications. Studies on supply chain networks explored SC procurement and sourcing networks and found that they can have a positive effect on SC suppliers and customers responsiveness $[34,35]$. Building on the fundamental research output showing the history of supply chain networks' structure and development, there are opportunities to construct SCF networks and future advancements in supply chain networks, these new opportunities such as sustainable financing depends on innovations. Hence, supply chain networks-based theories proposed new network perspectives that revealed innovative network structures and compositions in global SC financing [36, 37]. Prior studies showed significant connections between supply chain networks structures and supply chain companies' operations implementation, following a similar line of inquiry presented by the role of network brokerage [38]. Specifically, supply chain companies have the ability to expand supply chain networks structure globally when network features grow with advancing technologies and information flows, the important role of supply chain companies positions in the operations 
of networks is that it can increase the company's governing and negotiating power and facilitate financing through financial institutions and brokers [39].

supply chain companies that maintain a consistent, reliable, and operational set of activities within the supply chain networks experience momentous advantages and benefits in obtaining resources such as funding through crowdsourcing [40]. Predominantly, from the view of resource dependency theory, supply chain companies struggle to operate autonomously, as they require networks to accommodate the interdependencies in product and service flows, resource flows, and information flows [41]. These dependencies in SC markets create opportunities for supply chain companies to use the links to make considerable commitments in building sustainable technology driven supply chain networks. Some studies indicated that the interdependencies can either positively or negatively affect SC operations, and highlighted opportunities for further research [42]. According to Pfeffer and Salancik [43], interdependence is a continuous process in which supply chain companies can foster inter-corporation based on resource and information sharing. However, further studies demonstrated that the degree of interdependence is also a risk in resource dependency theory, so putting mitigating parameters in place to address disconnections within the network is an important condition. Basole, et al. [31] discussed that as supply chain networks is a global emerging field, risk management and business continuity packages are rolled out simultaneously. Therefore, the initial concerns raised [26] are considered in global supply chain networks.

Supply chain companies are taking advantage of the SC structure, practices, and resources in a single network, however with multi-layered hosts in the supply chain management databases, particularly SC financial institutions and brokers. The extensive research on supply chain management supports this concept, suggesting that supply chain companies are competent at managing high levels of operational and risk controls, including 
the ability to forecast SC echometric trends [44]. Furthermore, recent research showed that the direct financial outcomes associated with supply chain networks, such as cost saving, result from networks sharing brings together supply chain companies and customers in a technologically driven platform [45]. Certainly, this study [31] found that in purchasing, there is increasing support for supply chain networks in implementing resource management and distribution at the early stage. In addition, it is significant to understand whether or not there are benefits for supply chain companies that operate in a shared global supply chain network. However, few studies showed that there are strategic performance rewards, such as financial benefits, in a single multi-layered supply chain networks that connects supply chain companies in a unified technology driven resource system [33, 36, 39].

\subsection{Artificial Intelligence in Supply Chains}

supply chain management is encountering complex supply financial challenges such as cash flow shortages and tougher access to financial credits. SC success is rooted in the company's ability to innovate, implement, and operate new ideas that benefit the entire supply chain networks with end-to-end SC operations and information flows [46]. Thus, the introduction of AI to SCF and supply chain networks support technological advancements in supply chain management, such as technology driven materials acquisitions, digitalized cash flows systems, and automated networks to meet customer demand [47, 48]. The significance of digitization in supply chain management is that it enhances end-to-end SC operations and processes. Cutting-edge SC innovations can create the foundation for implementing AI and gaining the benefits of enriched data analytics tools consisting of intelligent networks and systems $[49,50]$. SC financing is becoming more data driven and focuses on alternative asset evaluations in which inventory, equipment, and warehouses become real substitute data [51, 52]. In addition, increasing significance of information in supply chain management, SC 
researchers and experts must continue to explore the benefits and challenges of managing large amounts of information [53,54]. According to Martínez-López and Casillas [51], AI has existed for decades, though it has not reached its full potential, especially for the supply chain management sector of the global economy.

However, it is worth noting that cyber risks such as cyber-attacks, malicious spying, and tempering are common to technology advancements such as AI, most of these cyber risks are invisible to detect in SC [55]. According to studies carried out by Radanliev, et al. [56], cyber systems such as AI technologies are transactional environment for exchange of valuable information on products and services, the safeguarding of interactions and information in essence is significant to supply chain companies. Furthermore, technology advancements such as AI, Big Data, and the Internet of Things are continuously investing in the security of data and developing new methods of shielding companies' valuable information from cyber risks and increasing confidence in AI technologies.

\subsubsection{Artificial intelligence networks}

The theory of artificial neural networks (ANNs) was developed to reflect the human brain, which uses the analogy of brain cells (neurons) in the design [57, 58]. Building on this concept, AI networks are connected like human memories and have the ability to learn and improve over time, which characterize its experience, distinct features, and complex analysis processes [59]. ANNs consist of several nodes that represent human neurons [60] with multiple links connecting these nodes, where each link has a set of algorithms programmed into it for efficiency and to process complex commands. Furthermore, these links connecting the nodes have weights that are the core for long-term memory storage, data processing, and data analytics. AI networks process data with systemic methods where the output of one neuron is transformed into the input for another, making every single process a pre-requisite 
for a new process [61]. According to Russell and Norvig [58], one of the functions of the weights in AI networks is to determine the strength or weakness of data passing through the links. The links provide an environment that hosts the values of the combined weights to form an AI process for learning. AI networks learning capabilities create an opportunity for deployment in the supply chain management sector, specifically by integrating SCF, supply chain companies, and suppliers' data, and creating patterns for interrelationships among data [62]. At the initialization of the AI networks, the system continues to improve its intelligence and performance with built-in learning algorithms by understanding SC operations and analyzing the optimum efficiency and required resources.

\subsubsection{Artificial intelligence systems}

AI systems are technologically driven systems with the ability to simulate human cognitive skills such as analyzing complex problems, visual analytics, optimum performance, and providing solutions [63]. Cheung, et al. [64] reported that AI systems have the capacity to perform analytic reasoning in complex problem-solving in contrast to human expertise problem-solving abilities. There are three fundamentals in AI systems: (1) knowledge networks, (2) interface engines, and (3) user interfaces.

Knowledge networks are the depository for data, facts, and rules of engagement during human activities, and are the basis for the resources that build AI systems [34, 37]. The interface engine is a collection of algorithms for problem-solving reasoning, which is also referred to as the brain of AI systems and is primarily responsible for conduction complex analyses such as solution search, algorithm reasoning, and providing an interface for the knowledge networks to leach on in an AI environment $[65,66]$, while the user interface connects the users with the system and supports user queries for interaction and communication [67]. 
Overwhelmingly, AI systems are designed with the concepts and operations for the domain in which they will be implemented. Thus, experts and practitioners who are knowledgeable about the tasks and role of the AI systems and human-system interaction will be practicable in problem solving $[53,68]$. In particular, AI systems showed tremendous progress in terms of increasing performance in most sectors [69], such as manufacturing, specifically in the automobile industry. Tesla car manufacturing reached 75 percent automation of the entire production process, where AI systems were implemented and led to higher performance and less waste. The application of AI technologies and systems in supply chain management, specifically the integration of SC operations and financing, is emerging, as evidenced in the successes of AI implementation in logistics and manufacturing.

\section{Research Meta-framework}

This study developed a meta-framework based on the discussion of the theoretical background on three key perspectives: SCF, supply chain networks and AI. These perspectives will be combined later in associations to find possible relationships. Table 1 shows how previous studies contributed to this research. To answer the research questions, this study will initially conceptualize the SCF [70], supply chain networks [31], and AI [71] perspectives. 
Table 1. Theoretical Review Summary

\begin{tabular}{|c|c|c|c|c|c|}
\hline $\begin{array}{l}\text { Citations (category } \\
\text { order) }\end{array}$ & Research Context & Research aims & Benefit to SCF & $\begin{array}{l}\text { Benefit to supply } \\
\text { chain networks }\end{array}$ & Benefit to AI \\
\hline$[12,72]$ & Supply Chain Finance & $\begin{array}{l}\text { In-depth comprehensive literature } \\
\text { review of studies on financial risk } \\
\text { management, challenges, and } \\
\text { opportunities }\end{array}$ & $\begin{array}{l}\text { Building conceptual } \\
\text { frameworks and models to } \\
\text { enhance the understanding of } \\
\text { SC financing. }\end{array}$ & $\begin{array}{l}\text { Finding associations from } \\
\text { the SCF literature to } \\
\text { support the meta- } \\
\text { framework in this research }\end{array}$ & $\begin{array}{l}\text { Supports investigations of } \\
\text { the relationships defined for } \\
\text { attributes of SCF and supply } \\
\text { chain networks }\end{array}$ \\
\hline$[34]$ & Supply Chain Networks & $\begin{array}{l}\text { Understanding the operations of } \\
\text { networks, the layers, and SC } \\
\text { operations }\end{array}$ & $\begin{array}{l}\text { Literature linking conceptual } \\
\text { frameworks and models in } \\
\text { SCF }\end{array}$ & $\begin{array}{l}\text { Finding associations from } \\
\text { the AI literature to support } \\
\text { the meta-framework in this } \\
\text { research }\end{array}$ & $\begin{array}{l}\text { Supports investigations of } \\
\text { the relationships defined } \\
\text { for attributes in the SCF } \\
\text { perspective }\end{array}$ \\
\hline$[52]$ & Artificial Intelligence & $\begin{array}{l}\text { Technology strategies, models, and } \\
\text { implementations incorporating new } \\
\text { supply chain networks and } \\
\text { operations }\end{array}$ & $\begin{array}{l}\text { The holistic approach } \\
\text { presented compares the } \\
\text { traditional SCF processes with } \\
\text { modern SCF processes, } \\
\text { traditional SCF verification }\end{array}$ & $\begin{array}{l}\text { Finding associations from the } \\
\text { AI literature to support the } \\
\text { meta-framework in this } \\
\text { research }\end{array}$ & $\begin{array}{l}\text { Supports investigations of } \\
\text { the relationships defined } \\
\text { for attributes from the SCF } \\
\text { and supply chain networks } \\
\text { perspectives }\end{array}$ \\
\hline$[73]$ & Fuzzy Set & $\begin{array}{l}\text { A set theoretic technique designed } \\
\text { for set theory analysis by creating } \\
\text { patterns of attributes defined by } \\
\text { numerous features and to generate } \\
\text { outcomes on the construction of } \\
\text { relationships }\end{array}$ & $\begin{array}{l}\text { Complementarity and } \\
\text { equifinality testing by } \\
\text { generating consistency and } \\
\text { solution coverage }\end{array}$ & $\begin{array}{l}\text { The combination system } \\
\text { supports the relationships } \\
\text { in the supply chain } \\
\text { networks and AI } \\
\text { perspectives }\end{array}$ & $\begin{array}{l}\text { A holistic approach targeting } \\
\text { new attributes in three } \\
\text { constructs mapped to } \\
\text { establish relationships for } \\
\text { data collection, theory } \\
\text { testing, and producing } \\
\text { outcomes }\end{array}$ \\
\hline
\end{tabular}

Note: Table 1 shows the underpinning literature that contributed to the four-research focus (supply chain finance, supply chain networks, artificial intelligence, and fuzzy set). 


\subsection{SCF perspective}

While prior studies provided many different descriptions of SCF, as they commonly state that the purpose is to provide cash flows for supply chain companies $[12,13]$. Therefore, this study identified three components in this perspective: (1) financial orientation (FO), (2) supply chain orientation (SCO), and (3) cash flows (CF).

The FO of the SCF perspective consists of a set of innovative solutions that financial institutions and brokers can rely on when making decisions when assessing applications by supply chain companies and suppliers, as they are the controlling actor in the SCF decisionmaking process. FO focuses on financing solutions that are important for payables or receivables and that are viable for the benefits of both the financial provider and supply chain companies and partners [74]. Thus, FO is a significant trigger in the SCF perspective, with the main objective of supporting sustainable SC operations.

The SCO component in the SCF perspective manages the records in the inventories such as the optimization of customer and supplier inventories, thus ensuring sustainable working capital to support daily SC operations in ensuring that market demands are met [75]. In addition, supply chain companies and their partners prioritize effective control and monitoring of financing and working capital, as Figure 1 shows. The SCO ensures sustainable availability of working capital or financing at the lowest rate to maintain SC operations. 


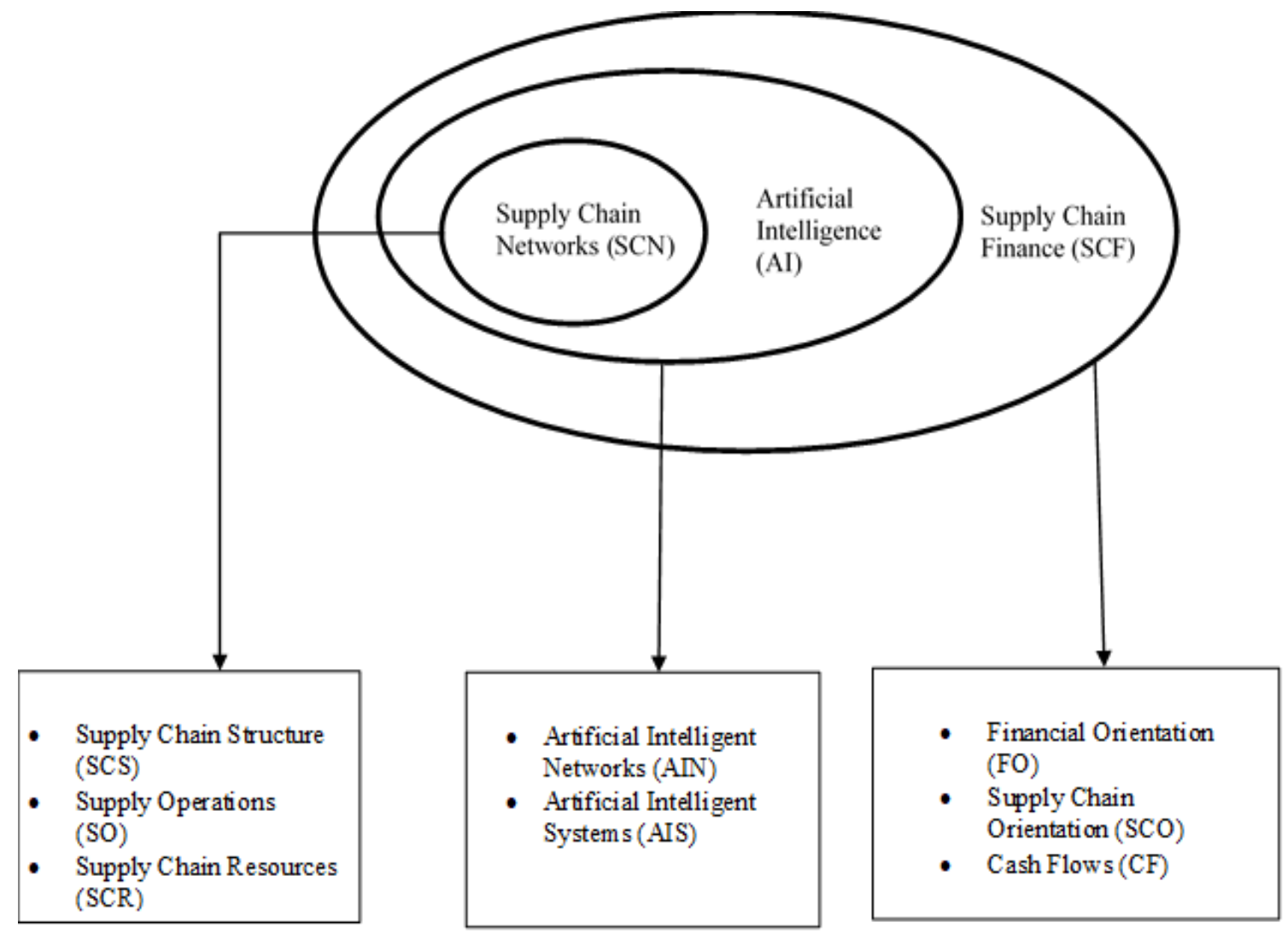

Figure 1. Supply Chain Finance Meta-Framework

Note: Figure 1 is the derived supply chain finance meta-framework indicating components of the three-research focus (supply chain finance, supply chain networks, and artificial intelligence) and components derived.

Cash flow (CF) is a vital resource for daily operations that support the company's activities and keep the business afloat [36]. In addition, CF demonstrates SC operations performance and indicates the direction in which cash is applied, allowing decision-makers to implement sustainable CF for SC operations, as this is an important factor when seeking financing from financial institutions or brokers.

\subsection{Supply chain networks and AI perspectives}

As Figure 1 shows, the supply chain networks, and AI perspectives combine to design sustainable networks consisting of strategic entities that integrate the SC associations of the members to create supply chain networks built on AI. There are three components associated 
with the supply chain networks perspective and two components associated with the AI perspective. According to Martinez, et al. [8], traditional supply chain networks are studied with a focus on understanding the existing connections to SC operations, leading to the strategic development of possible blockchain integration through existing channels. With this understanding, this study proposes an advanced supply chain networks implementation driven by AI technologies. It is already known that supply chain networks support innovative technology in supply chain management areas such as SC operations. However, there are emerging opportunities to develop sustainable supply chain networks for SC financing driven by AI technologies. Figure 1 shows that the AI-related components are embedded in the existing supply chain networks, indicating that existing information flows in the network are seamlessly transferred to AI knowledge networks for intelligence analysis.

\section{Research Method}

\subsection{Research design and data collection}

Following the design method [15], this study used a longitudinal survey with online participants to test the relationships and associations in the proposed meta-framework. A cross-sectional online survey was conducted in 2019, we selected active participants through research conferences, supply chain specific events, and use online platforms such as LinkedIn to engage in the survey exercise. This survey is for members, employees, and managers in supply chain organizations across the globe. Participants were also drawn from supply chain associated organizations such as technology for operations management. The questionnaire was developed through the research gaps identified from SCF, supply chain networks, and AI literature, the associations identified in Figure 1 transformed into sections of the survey. Consequently, we distributed the survey to 3,185 active targeted participants and received 432 surveys that included both partial and completed participations. This accounts 
for a response rate of $13 \%$, a study response rate that is consistent with extant research [76]. Since this study is unable to select partially completed surveys for analysis, our final sample number thus only consists of 205 completed surveys.

This study sample size consists of participants from across the globe, with North America accounting for $29 \%$ of the total survey which makes up for the largest share in terms of participant size. Experience with SCF platforms shows that $28 \%$ of the participants engage more than 5 times daily on the SCF platforms while $22.7 \%$ account for participants with 5 to 6 years working the SCF platforms. The research design was developed using this method, and the online survey was conducted using stratified sampling and the participants were proficient professionals in SC operations consistent with SC financing and have experience working with AI technologies. The participants were divided into specific demographic groups. As Table 2 shows, the expert profiles consist of gender, age, work locations, $\mathrm{SCF} /$ supply chain networks/AI usage, and SCF/supply chain networks/AI experience.

Table 2. Expert Profiles

\begin{tabular}{|c|c|c|c|c|c|}
\hline & No. & Percent & & No. & Percent \\
\hline Sex & & & SCF Platform Usage & & \\
\hline Male & 149 & 72.3 & Once a week & 2 & 1.0 \\
\hline \multirow[t]{2}{*}{ Female } & 57 & 27.7 & 2-4 times a week & 4 & 2.1 \\
\hline & & & 5-6 times a week & 11 & 5.2 \\
\hline Age & & & Once a day & 33 & 15.8 \\
\hline $18-24$ & 15 & 7.2 & 2-3 times a day & 47 & 22.9 \\
\hline $25-34$ & 33 & 15.9 & 4-5 times a day & 51 & 24.6 \\
\hline $35-44$ & 53 & 25.5 & More than 5 times a day & 59 & 28.4 \\
\hline $45-54$ & 63 & 30.8 & & & \\
\hline $55-64$ & 39 & 19.1 & SCF Platform experience & & \\
\hline \multirow[t]{2}{*}{65 or above } & 3 & 1.5 & Less than a year & 15 & 7.6 \\
\hline & & & $1-2$ year(s) & 22 & 10.5 \\
\hline Location & & & 3-4 years & 37 & 18.2 \\
\hline Africa & 26 & 12.5 & 5-6 years & 47 & 22.7 \\
\hline Asia & 36 & 17.5 & $7-8$ years & 46 & 22.3 \\
\hline Australia plus Oceania & 26 & 12.7 & $9-10$ years & 22 & 10.6 \\
\hline Europe & 53 & 25.8 & More than 10 years & 17 & 8.1 \\
\hline North America & 61 & 29.4 & & & \\
\hline South America & 4 & 2.1 & & & \\
\hline
\end{tabular}


Note: Table 2 shows the breakdown of the participants in the carried out underpinning literature that contribute to the study. The participants were sourced across the globe to ensure that the data analysis generates results that represent a world perspective.

\subsection{Data variables}

We obtained both dependent and independent variables using a multiple item, ranging from 1 symbolizes "strongly disagree" to 5 representing "strongly agree" on the five-point Likerttype scales. The use of five-point Likert-type scales ensures that the survey responses conform to statistical variability, due to difficulties in proof objective data relationship outcomes as shown in past studies $[77,78]$. therefore, as prior studies created a composite scale to capture relational and scalable dimensions of supply relationship, this study follows a similar approach on the scale return to represent what we intend to measure.

\subsection{Non-response bias}

Non-response is a frequently applied technique for assessing the bias in a research method, this study suggests that the participants that responded to the survey in the first month were at a $75 \%$ rate while $25 \%$ responses were completed later in the study variables. One-way nonresponse bias, performed at the entry-level suggests that there are no significant differences between the data gathered from an earlier stage and later responses, only that 1 in 26 which is $1.73 \%$ of the study variable. Concluding that non-response bias exists at the beginning of the time of participation is due to chance.

\subsection{Common method variance}

To minimize the impact of common method bias linked with reporting data sourced from one point such as survey, taking precautions in gathering the data, we followed guided procedures as suggested by [79]. the initial step taken in this study is to foremost ensure that most of the participants have experience working in the supply chain industries and are familiar with the technological platforms used in the sector. Most of the participants that responded to the 
survey have at least 3 years of work experience in the supply chain industries with sufficient managerial roles and knowledge about the increasing use of technology in the sector. Participants in the survey were reassured of the diligence ethical process in keeping their data anonymous. The inclusion of additional independent variables tends to reduce common method variance, the questions were organized in a strategic method to include intersperse entities.

\subsection{Analytical technique}

According to Oyemomi, et al. [80], Chen, et al. [81], a fuzzy set is a set-theoretic approach that evaluates theories, frameworks, and models with a deductive strategy driven by a positivist paradigm. Fuzzy sets are not a new technique for pure sciences and engineering but are an emerging method in the management and social sciences, as researchers without a science and engineering background encounter problems, such as approximate reasoning. However, the introduction of hybrid analytic techniques with fuzzy set logic that support fuzzy analyses in management and social sciences addressed these initial problems [82]. This study adopted relationship and association testing, as suggested in earlier work to test for Boolean expressions in the fuzzy set-theoretic approach for the four intersections in Figure 2. 


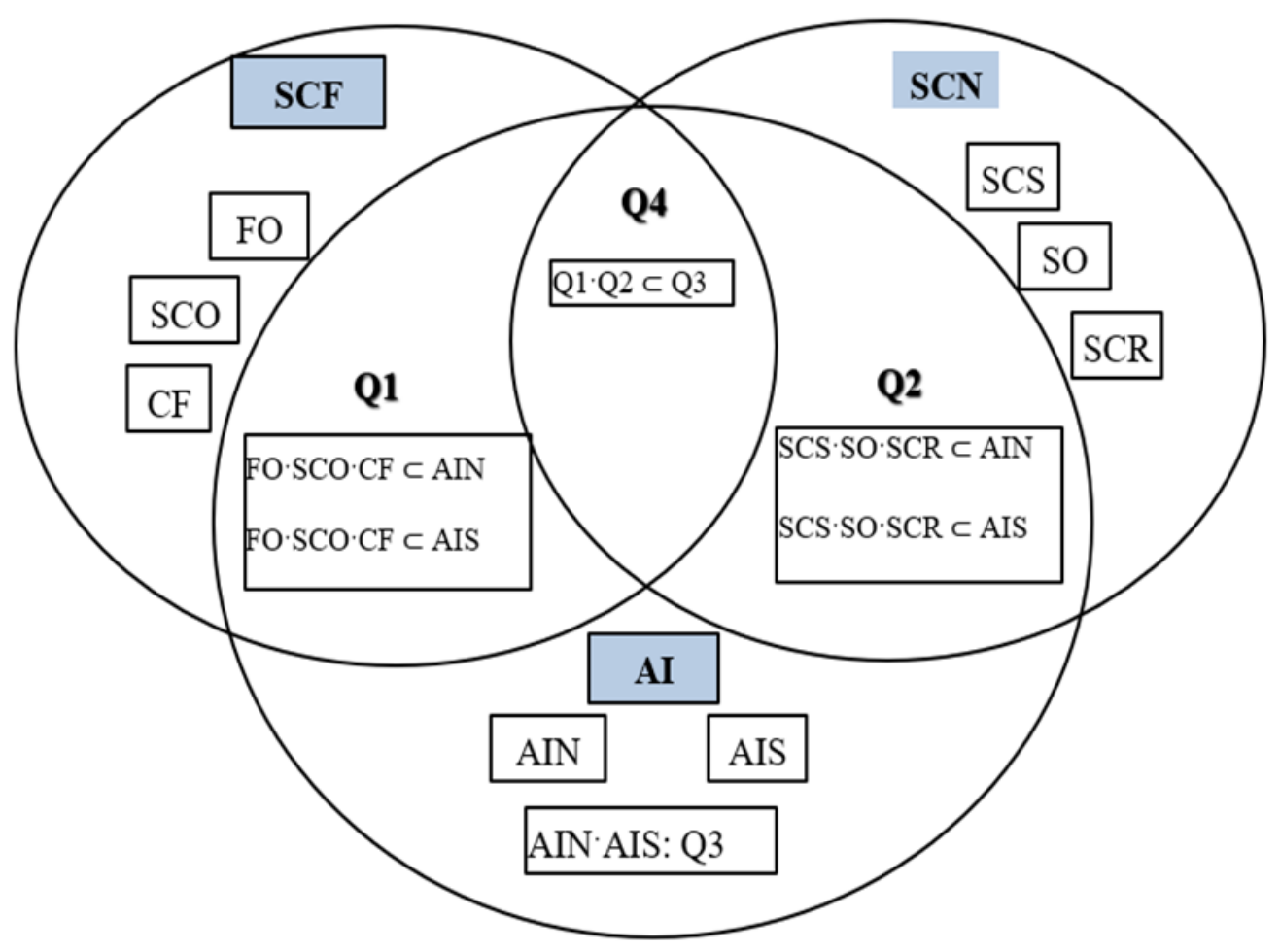

Figure 2. Integrated Meta-Framework
Note: $\mathrm{Q} 1=$ Association One
$\mathrm{Q} 2=$ Association Two
$\mathrm{SCF}=$ Supply Chain Finance
SCN = Supply Chain Networks
$\mathrm{FO}=$ Financial Orientation
SCS $=$ Supply Chain Structure
Q3 = Association Three
Q4 = Association Four
SCO $=$ Supply Chain Orientation
$\mathrm{CF}=$ Cash Flows
$\mathrm{SO}=$ Supply Operations
SCR $=$ Supply Chain Resources
$\mathrm{AI}=$ Artificial Intelligence
$\mathrm{AI}=$ Artificial Intelligent Systems
AIN $=$ Artificial Intelligent Networks

financial orientation (FO), (2) supply chain orientation (SCO), and (3) cash flows (CF).

This study proposes an eight-step process flowchart (see Figure 3). It consists of four loop relationships (represented in a double-line diamond) and three straw-in-the-wind relationships (represented in a single-line diamond) and shows the subsequent relationships used to discuss the outcomes from the analysis $[76,83,84]$. The flowchart is described as follows:

(1) A loop relationship for an expression that a solution pathway is reliable shows whether the consistency of the sufficiency analysis is greater than 0.7 of the solution pathways as defined in this study for the consistency threshold analysis. Any relationship that falls below the set threshold is eliminated from further analysis testing as this means that that relationship does not meet the acceptable reliability. A 
loop relationship for an expression with an accepted solution pathway shows whether the consistency of Q1 is greater than 0.7 , suggesting that any relationship that falls below the acceptance criteria in the solution pathway must be rejected and there should be no further analysis.

(2) A double-line diamond relationship for an expression that is strongly supported shows whether the consistency of Q2, Q3, and Q4 is less than or equal to 0.7, suggesting that any relationship that passes the acceptance criteria does not have significant contradictory proofs.

(3) A single-line diamond relationship for an expression that is not supported by itself, though would benefit subsequent relationships, can be described by the consistency of Q3 of less than or equal to 0.7. Furthermore, Q3 represents the type I consistency error, which usually has a lower acceptance threshold.

(4) A loop relationship for an expression for which a solution pathway is weakly supported shows whether the consistency for the sufficiency analysis result that Q1 is greater than Q3 in the solution pathways as defined for the consistency threshold analysis. Any relationship that falls below the set threshold is eliminated from further analysis testing, as the relationship does not meet the acceptable reliability.

(5) A double-line diamond relationship for a supported expression shows whether the consistency of Q4 is less than or equal to 0.7 , suggesting that any relationship that passes the acceptance criteria does not have a significant error reported during the analysis and supports the classification.

(6) A loop relationship for an expression for which a solution pathway is not weakly supported shows whether the consistency of Q2 is greater than 0.7 , suggesting that any relationship that falls below the acceptance criteria in the solution pathway can be improved and there is weak support for the classification. 
(7) A double-line diamond relationship for a supported expression shows whether the consistency of Q2 is greater than or equal to Q4, suggesting that any relationship that passes the acceptance criteria and partially supports the condition for Q2 and Q4 represents the type II consistency error, and it is usually equal to or higher than the acceptance threshold.

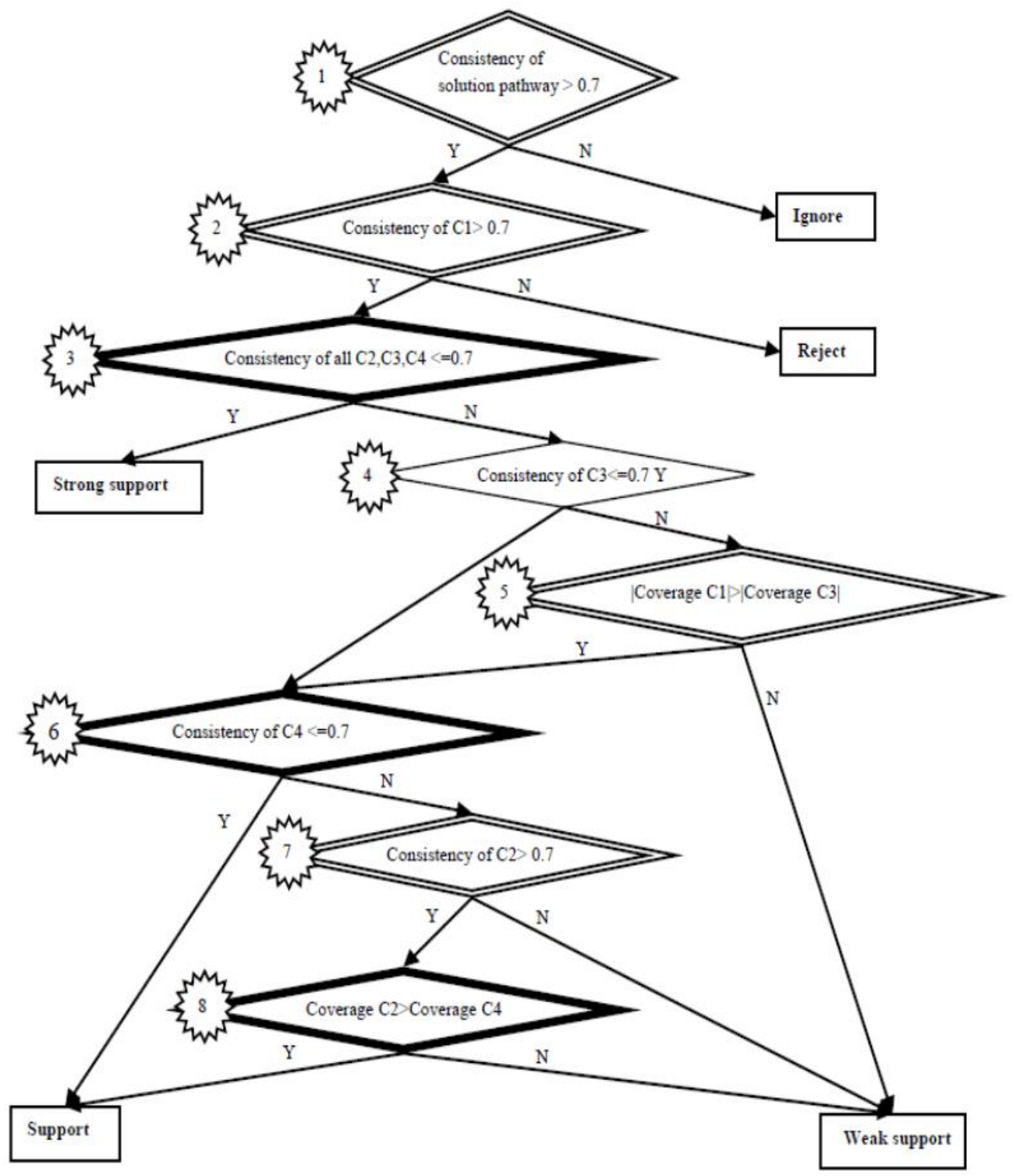

Figure 3. Flow Chart: fsQCA Analysis

Note: where cut-off consistency greater than 0.7 proceed to next stage consistency threshold, where preceding coverage greater than later, there is weak support. 


\subsection{Data Analysis and Results}

According to [83], complementarity and equifinality are two underlying features in the fuzzy set theoretic approach. It displays patterns of attributes and different results depending on the structure of the perspectives. The attributes in the perspectives are concerned with the present or absent conditions and the associations formed during conceptualization, rather than isolating the attributes from the perspectives. Furthermore, complementarity does exist if there is proof that causal factors show a match in their attributes and the results indicate a higher level, while equifinality exists if at least two unidentical pathways known as causal factors show the same level of results [85].

The results in Table 3 for the different perspectives indicate the part of the relationships that show empirical evidence for rejection and support. The results demonstrate that the relationships are more likely to yield rejection than support from this analysis. The solution pathway shows in the results, confirming the relationships. Consequently, supporting prior findings [86, 87], Figure 3 illustrates that a higher consistency level value directly results in a higher reliability of the relationship. The three combinations of attributes in the sufficiency analysis shows that the input efficiency either fails or passes the set consistency threshold requirement (consistency and coverage are 0.72 and 0.44 , respectively). 
Table 3. Results for Q1: Artificial Intelligence and Supply Chain Finance

\begin{tabular}{|c|c|c|c|c|c|c|c|}
\hline & \multicolumn{5}{|c|}{ Q1: FO'SCO'CF/AIN } & \multicolumn{2}{|c|}{$\begin{array}{l}\text { Q1: } \\
\text { FO'SCO CF/AIS }\end{array}$} \\
\hline Condition & S1 & S2 & S3 & S4 & S5 & S1 & S2 \\
\hline Consistency & 0.698892 & 0.692181 & 0.740252 & 0.733449 & 0.785004 & 0.970090 & 0.712693 \\
\hline Raw coverage & 0.236909 & 0.566492 & 0.164245 & 0.167030 & 0.091458 & 0.027005 & 0.445208 \\
\hline Unique coverage & 0.048374 & 0.336715 & 0.002648 & 0.005320 & 0.031859 & 0.010598 & 0.428800 \\
\hline Solution consistency & \multicolumn{5}{|c|}{0.686555} & \multicolumn{2}{|c|}{0.716547} \\
\hline Solution coverage & \multicolumn{5}{|c|}{0.665239} & \multicolumn{2}{|c|}{0.455806} \\
\hline $\mathrm{C} 1 \mathrm{H} \cdot \mathrm{S} \subset \mathrm{Y}$-Consistency & 0.75716 & 0.812902 & 0.827317 & 0.827317 & 0.988559 & 0.991696 & 0.916804 \\
\hline $\mathrm{C} 1: \mathrm{H} \bullet \mathrm{S} \subset \mathrm{Y}$-Raw coverage & 0.085357 & 0.067400 & 0.034448 & 0.034448 & 0.008089 & 0.006429 & 0.054261 \\
\hline $\mathrm{C} 2: \sim \mathrm{H} \bullet \mathrm{S} \subset \mathrm{Y}$-Consistency & 0.689295 & 0.692412 & 0.739000 & 0.731484 & 0.786105 & 0.959823 & 0.711222 \\
\hline $\mathrm{C} 2: \sim \mathrm{H} \bullet \mathrm{S} \subset \mathrm{Y}$-Raw coverage & 0.191634 & 0.565667 & 0.163395 & 0.166122 & 0.092622 & 0.027701 & 0.435212 \\
\hline $\mathrm{C} 3: \mathrm{H} \bullet \sim \mathrm{S} \subset \sim \mathrm{Y}$ - Consistency & 0.600079 & 0.466213 & 0.466213 & 0.466213 & 0.466213 & 0.548037 & 0.577609 \\
\hline $\mathrm{C} 3: \mathrm{H} \bullet \sim \mathrm{S} \subset \sim \mathrm{Y}$-Raw coverage & 0.058389 & 0.074411 & 0.074411 & 0.074411 & 0.074411 & 0.076858 & 0.074661 \\
\hline $\mathrm{C} 4: \sim \mathrm{H} \bullet \sim \mathrm{S} \subset \mathrm{Y}$-Consistency & 0.535569 & 0.476600 & 0.532806 & 0.534341 & 0.512781 & 0.446069 & 0.388852 \\
\hline $\mathrm{C} 4: \sim \mathrm{H} \bullet \sim \mathrm{S} \subset \mathrm{Y}$-Raw coverage & 0.841081 & 0.505483 & 0.860575 & 0.859848 & 0.864034 & 0.910765 & 0.582426 \\
\hline Solution pathway result & Ignore & Ignore & Support & Support & Support & Support & Support \\
\hline $\begin{array}{l}\text { Combined solution unique } \\
\text { pathway } \\
\text { Coverage of result }\end{array}$ & & & \multicolumn{3}{|c|}{0.039827} & \multicolumn{2}{|c|}{0.439398} \\
\hline Overall pathway result & \multicolumn{5}{|c|}{ Support } & \multicolumn{2}{|c|}{ Support } \\
\hline
\end{tabular}

Note: S1 = Solution One

S2 $=$ Solution Two

S3 = Solution Three

S4 = Solution Four

S5 $=$ Solution Five

In Table 4, the relationships indicate support that the analysis generates attributes in the perspectives above the combined solution pathways than in Table 4. As shown, the type II error of a false negative is one form of contradiction between the relationships and results which is ignored, as defined in Figure 3. These findings indicate the least likely attributes in the perspectives show that the existing relationships hold, supporting the higher consistency level of the associations and stronger support for further relationships. Hence, this analysis can introduce additional causal conditions of similar attributes not yet shown in the current relationships by tracking back to the relationship mapping data, thus finding common 
attributes in the existing perspectives that may explain the undefined variance from the existing relationships.

Table 4. Results for Q2: Artificial Intelligence and Supply Chain Networks

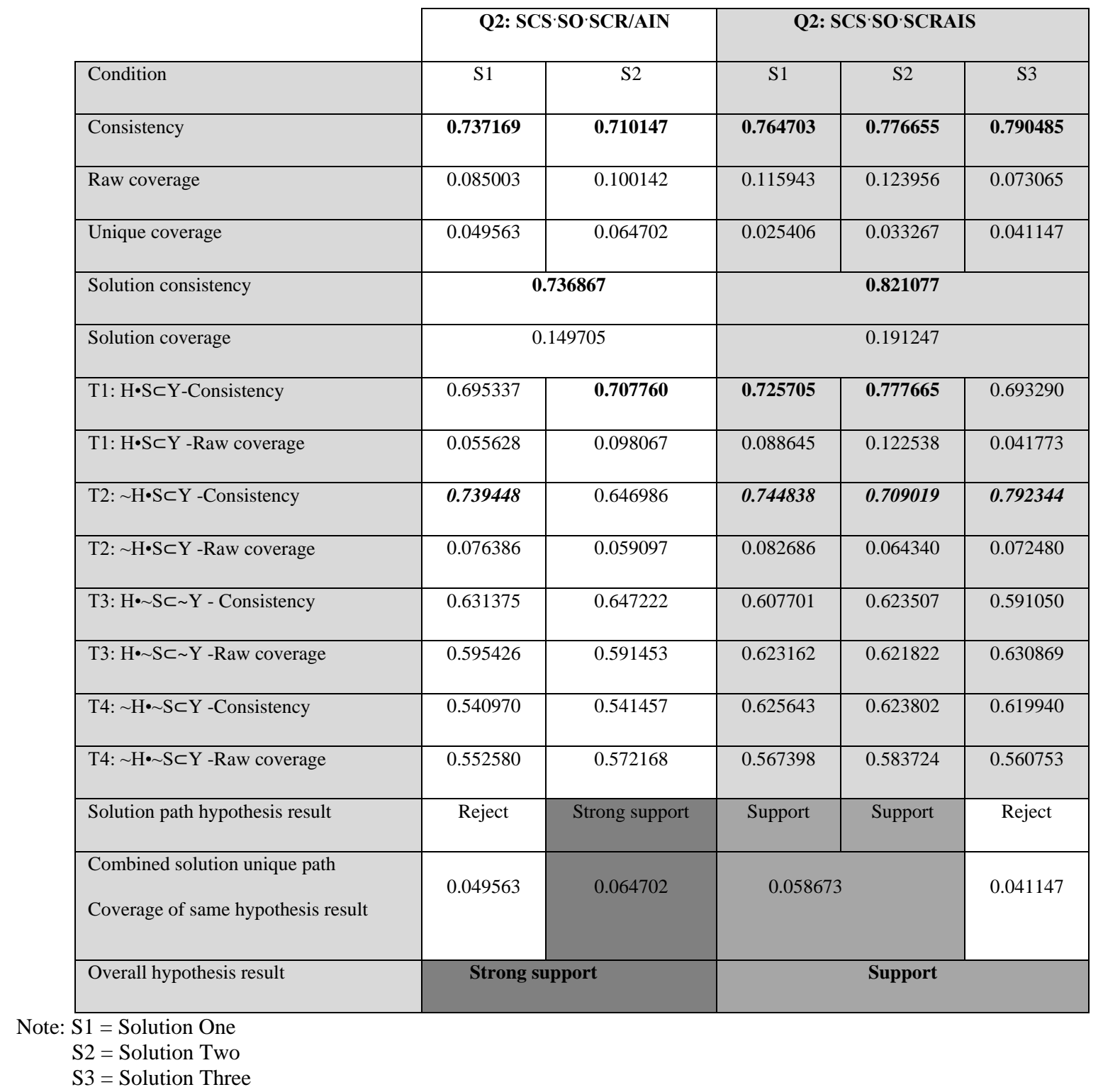

The results in Table 5 for the combined solution pathway for consistency and coverage indicate support for most attributes in the perspectives, indicating a type I error (or a false positive) in the form of contradicting variances in the relationships. In addition, the higher consistency level of the associations supports higher values to delimit the 
relationships. Thus, some unconfirmed attributes indicate a restriction of the current relationships.

Table 5. Results for Q3: Significant Roles of Artificial Intelligence

\begin{tabular}{|c|c|c|c|}
\hline & Q3: Q1-AIN/AIS & Q3: Q2-AIN/AI & \\
\hline Condition & S1 & S1 & S2 \\
\hline Consistency & 0.710821 & 0.765686 & 0.765449 \\
\hline Raw coverage & 0.161335 & 0.271478 & 0.276201 \\
\hline Unique coverage & 0.161335 & 0.005228 & 0.009951 \\
\hline Solution consistency & 0.710821 & 0.768799 & \\
\hline Solution coverage & 0.161335 & 0.281429 & \\
\hline $\mathrm{C} 1 \mathrm{H} \cdot \mathrm{H} \cdot \mathrm{S} \subset \mathrm{Y}-$ Consistency & 0.691323 & 0.759535 & 0.759724 \\
\hline $\mathrm{C} 1: \mathrm{H} \bullet \mathrm{S} \subset \mathrm{Y}-\mathrm{Raw}$ coverage & 0.087053 & 0.187811 & 0.188006 \\
\hline $\mathrm{C} 2: \sim \mathrm{H} \bullet \mathrm{S} \subset \mathrm{Y}$-Consistency & 0.707803 & 0.741407 & 0.742004 \\
\hline $\mathrm{C} 2: \sim \mathrm{H} \bullet \mathrm{S} \subset \mathrm{Y}$-Raw coverage & 0.160089 & 0.175810 & 0.180727 \\
\hline 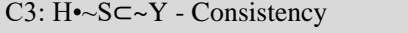 & 0.560523 & 0.623238 & 0.623238 \\
\hline C3: H• Sᄃ Y -Raw coverage & 0.665845 & 0.640238 & 0.640238 \\
\hline $\mathrm{C} 4: \sim \mathrm{H} \bullet \sim \mathrm{S} \subset \mathrm{Y}$-Consistency & 0.597557 & 0.559862 & 0.556151 \\
\hline C4: $\sim \mathrm{H} \bullet \sim \mathrm{S} \subset \mathrm{Y}$-Raw coverage & 0.426468 & 0.417932 & 0.411692 \\
\hline Solution pathway result & Reject & Support & Support \\
\hline $\begin{array}{l}\text { Combined solution unique pathway } \\
\text { Coverage of result }\end{array}$ & 0.161335 & 0.015179 & \\
\hline Overall pathway result & Reject & Sup & \\
\hline
\end{tabular}

Note: S1 = Solution One

$\mathrm{S} 2=$ Solution Two

The analysis in Table 6 of the combined solution pathway indicates that neither prediction in the relationships nor coverage by attributes definitions for the perspectives are strongly supported in the SCF for the role of AI technologies in supply chain networks. Therefore, alternative variances, as understood by experts and researchers, provide better supporting conditions for the definitions of the relationships in Q4. Five out of the six 
pathways are equal to or greater than the defined threshold, indicating that the relationships between the perspectives can benefit from trade-offs. Furthermore, there are similarities in the results for the unique coverage, signaling significantly high efficiency input linked directly with the variance from the causal conditions.

Table 6. Results for Q4: Consistency in Supply Chain Financing

\begin{tabular}{|c|c|c|c|c|c|c|c|}
\hline \multirow[b]{2}{*}{ Condition } & \multicolumn{7}{|c|}{ Q4: Q1-Q2/Q3 } \\
\hline & S1 & S2 & S3 & S4 & S5 & S6 & S7 \\
\hline Consistency & $\begin{array}{c}0.79315 \\
6\end{array}$ & $\mathbf{0 . 7 7 7 0 8 8}$ & 0.775229 & $\mathbf{0 . 7 5 5 3 1 1}$ & 0.860643 & 0.762031 & 0.781217 \\
\hline Raw coverage & $\begin{array}{c}0.15104 \\
9\end{array}$ & 0.134623 & 0.142804 & 0.125786 & 0.130888 & 0.070419 & 0.109356 \\
\hline Unique coverage & $\begin{array}{c}0.06287 \\
5 \\
\end{array}$ & 0.066940 & 0.047280 & 0.029209 & 0.048338 & 0.017503 & 0.013124 \\
\hline Solution consistency & \multicolumn{7}{|c|}{0.760072} \\
\hline Solution coverage & \multicolumn{7}{|c|}{0.430462} \\
\hline $\mathrm{C} 1: \mathrm{H} \bullet \mathrm{S} \subset \mathrm{Y}-\mathrm{Consistency}$ & $\begin{array}{c}0.78560 \\
2 \\
\end{array}$ & 0.805686 & 0.775045 & 0.825182 & 0.862248 & 0.757407 & 0.780279 \\
\hline $\mathrm{C} 1 \mathrm{H} \cdot \mathrm{S} \subset \mathrm{Y}$-Raw coverage & $\begin{array}{c}0.08418 \\
1\end{array}$ & 0.080744 & 0.141481 & 0.098665 & 0.130956 & 0.069269 & 0.107682 \\
\hline $\mathrm{C} 2: \sim \mathrm{H} \bullet \mathrm{S} \subset \mathrm{Y}-\mathrm{Consistency}$ & $\begin{array}{c}0.80809 \\
0\end{array}$ & 0.785524 & 0.855294 & 0.754137 & 0.837106 & 0.695468 & 0.852027 \\
\hline $\mathrm{C} 2: \sim \mathrm{H} \bullet \mathrm{S} \subset \mathrm{Y}$-Raw coverage & $\begin{array}{c}0.14677 \\
6\end{array}$ & 0.127047 & 0.083998 & 0.124586 & 0.063875 & 0.050274 & 0.076678 \\
\hline $\mathrm{C} 3: \mathrm{H} \bullet \sim \mathrm{S} \subset \sim \mathrm{Y}$ - Consistency & $\begin{array}{c}0.51714 \\
2\end{array}$ & 0.518360 & 0.534262 & 0.516897 & 0.548324 & 0.526356 & 0.524705 \\
\hline $\mathrm{C} 3: \mathrm{H} \bullet \mathrm{S} \subset \sim \mathrm{Y}$-Raw coverage & $\begin{array}{c}0.56409 \\
2\end{array}$ & 0.563832 & 0.540307 & 0.568478 & 0.559569 & 0.568297 & 0.550638 \\
\hline $\mathrm{C} 4: \sim \mathrm{H} \bullet \sim \mathrm{S} \subset \mathrm{Y}$-Consistency & $\begin{array}{c}0.57340 \\
5\end{array}$ & 0.571344 & 0.545416 & 0.549898 & 0.545416 & 0.545416 & 0.545416 \\
\hline $\mathrm{C} 4: \sim \mathrm{H} \bullet \sim \mathrm{S} \subset \mathrm{Y}$-Raw coverage & $\begin{array}{c}0.47123 \\
5\end{array}$ & 0.475278 & 0.493535 & 0.472495 & 0.493535 & 0.493535 & 0.493535 \\
\hline Solution pathway result & Support & Support & Support & Support & Support & $\begin{array}{l}\text { Strong } \\
\text { support }\end{array}$ & Support \\
\hline $\begin{array}{l}\text { Combined solution unique } \\
\text { pathway } \\
\text { Coverage of result }\end{array}$ & \multicolumn{5}{|c|}{0.267766} & 0.017503 & \\
\hline Overall pathway result & \multicolumn{7}{|c|}{ Support } \\
\hline
\end{tabular}

Note: S1 = Solution One

S2 = Solution Two

S3 = Solution Three

S4 $=$ Solution Four

S5 = Solution Five

S6 $=$ Solution Six

S7 $=$ Solution Seven

To fully understand the Q4 outcomes, it is important to discuss the outcomes from Q1, Q2, and Q3 simultaneously. Q1 and Q2 alone are not adequate to support high input efficiency, indicating that AI will fade-out without a correlation with supply chain networks. Therefore, the combination of the two perspectives is highly significant to the relationships to 
create high input efficiency. However, Q3, which considers all attributes in the AI perspectives, rejects the associated attributes from Q1, but shows weak support for A2, indicating that the conditions are peripheral or are conditions with less supporting variance. This explains the weak support in the attributes of their relationships. Q4 outcomes show that this study considers the relationships of the attributes of the relations between Q1 and Q2, as the roles of Q3 have explanatory control over the outcomes from redefining the impact of both associations.

This study developed a meta-framework for the role of AI in building sustainable SC financing using supply chain networks that are currently operating in SC activities by exploring novel findings that individually or in combination established links to build on for the three perspectives. An online survey was carried out with a stratified sample to test the meta-framework, and the data were used to further categorize the relationships among the perspectives. The empirical analysis shows important results that further the understanding of these associations.

The findings show that Table 3. results for Q1: FO SCO CF/AIN/AIS where the relationships of both artificial intelligence and supply chain finance constructs in the solution pathway result are supported. Cheung, et al. [64], highlight the significant role of AI in aiding innovative organizational operability and providing sustainable competitive advantages. As findings in Table 4. results for Q2: SCS SO SCR/AIN/AIS demonstrate support for constructs associations. More specifically, a section of Table 4. Q2: SCS $\cdot$ SO $\cdot$ SCR/AIN (S2) indicates that there is strong support for implementing artificial intelligence networks with existing supply chain networks. AI technologies were implemented, there has been significant improvement to the operations and processes, complex tasks are simplified using AI algorithms. 


\section{Discussion}

The findings in this study demonstrate the important role of AI as shown in the associations of the construct with SCF and supply chain networks, the introduction of AI in practice as a tacit control of the supply chain networks as a resource for secure access to financial resources, and unavoidably includes other resources that benefit the SC. Consequently, AI puts together supply chain networks with SCF criteria set by the financial institutions and brokers, suggesting two themes. First, ensure that the dependence controls are balanced and that access to resources is mutually beneficial to all parties by consistent monitoring of performance. Second, network system homogeneities, structure and operations become a unified network that identifies resources usage and efficiency.

The purpose of this study was to find out the role of AI as a technology tool for stimulating SC financing through existing supply chain networks. Explicitly, we carried out a complimentary analysis to explore the role of an AI-enabled SCN in facilitating sustainable supply chain financing for supply chain companies. Three perspectives: supply chain finance, supply chain networks, and artificial intelligence were developed following the development of SCF meta-framework, four intersections: Q1 = association one, Q2 = association two, Q3 = association three, and Q4 = association four between the three perspectives were further developed.

The outcomes gathered after analysis of validated data from questionnaire show that AI-enabled SCN is important in minimizing the issue of financing which limited assets available in supply networks. Consequently, the complementarity of the three perspectives; SCF, SCN, and AI technology further enhanced into four intersections relationship mapping by constructing entities association from each perspective as shown in Figure 2. The results from Table 3, suggest that the testing of the relationship of AI and SCF perspectives and their entities financial orientation, supply chain orientation, and cash flows of SCF and artificial 
intelligence networks and artificial intelligent systems of AI are supported. Furthermore, the outcomes in Table 3 concur with the fuzzy set relationship mapping which discussed the consistency and coverage requirement in Figure 3, suggesting that the implementation of AI technology to supply chain financing provides vital information on how the distribution of financial services can influence performance in supply chain. This result demonstrates consistent with the findings of [15] which discussed the significant role of AI in financing the food and drink industry. Hence, the relationship between AI and SCF perspectives illustrates support in the implementation of AI-enabled solutions to the financial services available in supply chain.

In Table 4, the result for artificial intelligence and supply chain networks for their entities artificial intelligent networks, artificially intelligent systems, supply chain structure, supply chain resources and supply operations show strong support for the relationship as the consistency and coverage suggest that the association significantly influence the financial services for supply chain. The positive complimentary association further support AI and SCN perspectives relationship mapping, with constructs' consistency and coverage meeting the set requirement in Figure 3. Furthermore, there is support for the results Table 5 significant roles of artificial intelligence and Table 6 consistency in supply chain financing, except for the relationship mapping in Table 4 for AI perspective entities artificial intelligent networks and artificial intelligent systems which shows a rejected relationship. The condition $\mathrm{S} 1$ is rejected as it is the only association that is tested with only one condition.

The findings strengthen the importance of the application of AI-enabled SCN to support supply chain financial services. In practice, AI-enabled SCN advances the understanding of challenges in financial services for supply chain, suggesting the exploration of the assets available through the supply chain $[2,15,88,89]$. Other opportunities that are available with the supply chain networks include partnership in financial services, suppliers, 
financial service institutions, and supply chain industry benefits from AI driven financial services integrated into the network systems in the supply chain.

\subsection{Implications for Research}

This study proposed complementarity of SCF, supply chain networks, and AI technologies to understand the explanatory influence by linking theoretical views that did not consider these connections previously. This study used the perspective of complex causality to analyze the data and generate empirical findings. This paper provided a new understanding of the proposed complementarity by contributing a holistic evaluation of all attributes of the three perspectives, building relationships, and presenting findings that identify the significance of each association in an effort to build sustainable SC financing using AI-driven supply chain networks. Therefore, this research builds on existing studies $[9,90]$ that call for further work on SCF and supply chain networks, while contributing to the role of AI by exploring the conditions under different scenarios and complementarity values. The online survey data supports the solution coverage across attribute dimensions by analyzing complementarity efficiency using defined threshold requirements. This study answers the call for enquiries into how supply chain networks (the environment) and supply chain companies can strategically allocate all resources for cascading SC financing. Most importantly, the fuzzy set theory technique accounts for complex causality to yield novel empirical findings.

This paper contributes to the SCF, supply chain networks, and AI literature by developing a meta-framework that examines the integration of AI technology in existing supply chain networks, which can provide alternative SC financing by relying on the available resources and enabling financial institutions and brokers to partner with supply chain companies and suppliers through AI-enabled networks. 


\subsection{Implications for Practice}

The comprehensive theoretical review and in-depth empirical analysis of the complex casualty on the role of AI in building sustainable supply chain networks for SC financing in this study allow supply chain companies and suppliers to consider their organizational strategies in their effort to create cascading networks and implement compatible sustainable solutions. As proposed in the relationships, the attributes from each perspective combinations demonstrate support for solution pathways in the outcomes, supply chain companies prioritizing innovative resources to ensure that AI-driven supply chain networks are sustainable assets for SC financing, as untapped potential resources are hiding with the layers in the networks in which SC operations are embedded.

supply chain companies have long been searching for alternative sources of financing that consider current assets such as operations and networks in SCF. With an innovative deployment of AI, financial institutions and brokers can support SC operations through AI technology, providing financial services based on transitions through AI-enabled networks. Therefore, financial risks are reduced, and AI-enabled networks can filter through complex and risk-exposed operations within SCs. The results reported here are important for financial opportunities for both short- and long-term sustainability on SC.

\subsection{Limitations and future research directions}

Given the research aims and scope, this study has limitations that offer opportunities for future research. This study identified and analyzed SCF, supply chain networks, and AI technologies, focusing on sustainable SC financing through supply chain networks, though does not address other perspectives, such as supply chain companies' policies, political strategies, and negotiation strategies. Similarly, the sample during the data collection process targeted supply chain management experts and researchers, specifically those focusing on supply chain networks and financing, who engage most frequently in SC innovations by 
demography. However, financial analysts may be of relevance for future research. Given that previous research focuses on SCF risk management and financial challenges, to understand risks and issues in $\mathrm{SC}$ financing, the influence of $\mathrm{AI}$ as a possible sustainable solution to risks around SC financing will permit future research to proceed with new data sets. In the same line, this study did not consider the financial impact of implementing AI technologies, which is another interesting area for future research.

This cross-sectional research aimed to provide an in-depth understanding of the relationships among the three perspectives, using a balanced sample to mitigate gaps in previous studies by analyzing data in terms of diverse demography rather than from selected regions. However, since some studies consider results from a single location, future research can compare the complementarity, consistency, and coverage of single versus multiple locations, which will directly enrich the understanding of the findings presented here. 
References

[1] S. A. Robbins, "AI and the path to envelopment: knowledge as a first step towards the responsible regulation and use of AI-powered machines," AI\&Society: the journal of human-centered systems and machine intelligence, pp. urn:issn:0951-5666, 2019.

[2] A. Moretto, L. Grassi, F. Caniato, M. Giorgino, and S. Ronchi, "Supply chain finance: From traditional to supply chain credit rating," Journal of Purchasing and Supply Management, vol. 25, no. 2, pp. 197-217, 2019/03/01/ 2019, doi: https://doi.org/10.1016/j.pursup.2018.06.004.

[3] X. Pu, L. Chong Alain Yee, Z. Cai, K. Lim Ming, and H. Tan Kim, "Leveraging open-standard interorganizational information systems for process adaptability and alignment: An empirical analysis," International Journal of Operations \&amp; Production Management, vol. 39, no. 6/7/8, pp. 962-992, 2019, doi: 10.1108/IJOPM12-2018-0747.

[4] C. Wang, X. Fan, and Z. Yin, "Financing online retailers: Bank vs. electronic business platform, equilibrium, and coordinating strategy," European Journal of Operational Research, vol. 276, no. 1, pp. 343-356, 2019/07/01/ 2019, doi: https://doi.org/10.1016/j.ejor.2019.01.009.

[5] L. M. Gelsomino, R. de Boer, M. Steeman, and A. Perego, "An optimisation strategy for concurrent Supply Chain Finance schemes," Journal of Purchasing and Supply Management, vol. 25, no. 2, pp. 185-196, 2019/03/01/ 2019, doi: https://doi.org/10.1016/j.pursup.2018.07.004.

[6] M. Du, Q. Chen, J. Xiao, H. Yang, and X. Ma, "Supply Chain Finance Innovation Using Blockchain," Ieee T Eng Manage, vol. 67, no. 4, pp. 1045-1058, 2020, doi: 10.1109/TEM.2020.2971858.

[7] S. F. Wamba and S. Akter, "Understanding supply chain analytics capabilities and agility for data-rich environments," International Journal of Operations \& Production Management, vol. 39, no. 6/7/8, pp. 887-912, 2019, doi: 10.1108/ijopm-01-20190025.

[8] V. Martinez, M. Zhao, C. Blujdea, X. Han, A. Neely, and P. Albores, "Blockchaindriven customer order management," International Journal of Operations \&amp; Production Management, vol. 39, no. 6/7/8, pp. 993-1022, 2019, doi: 10.1108/IJOPM-01-2019-0100.

[9] T. Tunca and W. Zhu, "Buyer Intermediation in Supplier Finance," Manage Sci, vol. 64, no. 12, p. 5631, 2018, doi: 10.1287/mnsc.2017.2863.

[10] M.-L. Tseng, K.-J. Wu, J. Hu, and C.-H. Wang, "Decision-making model for sustainable supply chain finance under uncertainties," International Journal of Production Economics, vol. 205, pp. 30-36, 2018/11/01/ 2018, doi: https://doi.org/10.1016/j.ijpe.2018.08.024.

[11] S. C. Sperber, "The Top Managers' Impact on Opening the Organizational Culture to Innovation," (in English), Int J Innov Manag, vol. 21, no. 02, Feb 2017, doi: 10.1142/s1363919617500141.

[12] M. Gelsomino Luca, R. Mangiaracina, A. Perego, and A. Tumino, "Supply chain finance: a literature review," International Journal of Physical Distribution \&amp; Logistics Management, vol. 46, no. 4, 2016, doi: 10.1108/IJPDLM-08-2014-0173.

[13] X. Xu, X. Chen, F. Jia, S. Brown, Y. Gong, and Y. Xu, "Supply chain finance: A systematic literature review and bibliometric analysis," International Journal of Production Economics, vol. 204, pp. 160-173, 2018, doi: 10.1016/j.ijpe.2018.08.003. 
[14] S. Marn-Ling, S. Chen-Chi, C. Kuo Lane, and L. Huei, "Security Modeling on the Supply Chain Networks," Journal of Systemics, Cybernetics and Informatics, vol. 5, no. 5, pp. 53-58, 2007.

[15] F. Olan, S. Liu, J. Suklan, U. Jayawickrama, and E. O. Arakpogun, "The role of Artificial Intelligence networks in sustainable supply chain finance for food and drink industry," International Journal of Production Research, pp. 1-16, 2021, doi: 10.1080/00207543.2021.1915510.

[16] B. Xing, W.-J. Gao, K. Battle, T. Marwala, and F. V. Nelwamondo, "Artificial Intelligence in Reverse Supply Chain Management: The State of the Art," Webist 2009: Proceedings of the Fifth International Conference on Web Information Systems and Technologies, 2010.

[17] P. A. Hennelly, J. S. Srai, G. Graham, and S. Fosso Wamba, "Rethinking supply chains in the age of digitalization," Production Planning \& Control, vol. 31, no. 2-3, pp. 93-95, 2020/02/17 2020, doi: 10.1080/09537287.2019.1631469.

[18] K. S. Lam Hugo, "Doing good across organizational boundaries: Sustainable supply chain practices and firms' financial risk," International Journal of Operations \&amp; Production Management, vol. 38, no. 12, pp. 2389-2412, 2018, doi: 10.1108/IJOPM02-2018-0056.

[19] H.-C. Pfohl and M. Gomm, "Supply chain finance: optimizing financial flows in supply chains," Logistics Research, vol. 1, no. 3, pp. 149-161, 2009/12/01 2009, doi: 10.1007/s12159-009-0020-y.

[20] F. Caniato, L. M. Gelsomino, A. Perego, and S. Ronchi, "Does finance solve the supply chain financing problem?," Supply Chain Management: An International Journal, vol. 21, no. 5, pp. 534-549, 2016, doi: 10.1108/SCM-11-2015-0436.

[21] M. Ben-Daya, E. Hassini, and Z. Bahroun, "Internet of things and supply chain management: a literature review," International Journal of Production Research, vol. 57, no. 15-16, pp. 4719-4742, 2019/08/29 2019, doi:

10.1080/00207543.2017.1402140.

[22] C. Bals, "Toward a supply chain finance (SCF) ecosystem - Proposing a framework and agenda for future research," Journal of Purchasing and Supply Management, vol. 25, no. 2, 2019, doi: 10.1016/j.pursup.2018.07.005.

[23] M. M. Hasan and A. Cheung, "Organization capital and firm life cycle," J Corp Financ, vol. 48, pp. 556-578, 2018, doi: 10.1016/j.jcorpfin.2017.12.003.

[24] S. Carnovale, D. S. Rogers, and S. Yeniyurt, "Broadening the perspective of supply chain finance: The performance impacts of network power and cohesion," Journal of Purchasing and Supply Management, vol. 25, no. 2, pp. 134-145, 2019/03/01/ 2019, doi: https://doi.org/10.1016/j.pursup.2018.07.007.

[25] D. Lekkakos Spyridon and A. Serrano, "Supply chain finance for small and medium sized enterprises: the case of reverse factoring," International Journal of Physical Distribution \&amp; Logistics Management, vol. 46, no. 4, 2016, doi: 10.1108/IJPDLM-07-2014-0165.

[26] N. Osadchiy, V. Gaur, and S. Seshadri, "Systematic Risk in Supply Chain Networks," Manage Sci, vol. 62, no. 6, pp. 1755-1777, 2015, doi: 10.1287/mnsc.2015.2187.

[27] L. Zhao and A. Huchzermeier, "Managing supplier financial distress with advance payment discount and purchase order financing," Omega, vol. 88, pp. 77-90, 2019/10/01/ 2019, doi: https://doi.org/10.1016/j.omega.2018.10.019.

[28] L. Zhao and A. Huchzermeier, "Operations-finance interface models: A literature review and framework," European Journal of Operational Research, vol. 244, no. 3, pp. 905-917, 2015. 
[29] Y. Zhu, L. Zhou, C. Xie, G.-J. Wang, and T. V. Nguyen, "Forecasting SMEs' credit risk in supply chain finance with an enhanced hybrid ensemble machine learning approach," International Journal of Production Economics, vol. 211, pp. 22-33, 2019, doi: 10.1016/j.ijpe.2019.01.032.

[30] K. J. Mizgier, S. M. Wagner, and M. P. Jüttner, "Disentangling diversification in supply chain networks," International Journal of Production Economics, vol. 162, pp. 115-124, 2015, doi: 10.1016/j.ijpe.2015.01.007.

[31] R. C. Basole, M. A. Bellamy, H. Park, and C. d'Aspremont, "Visualization of Innovation in Global Supply Chain Networks," Decision Sci, vol. 48, no. 2, pp. 288306, 2017, doi: 10.1111/deci.12213.

[32] A. D'Ignazio and E. Giovannetti, "Continental differences in the clusters of integration: Empirical evidence from the digital commodities global supply chain networks," International Journal of Production Economics, vol. 147, p. 486, 2014.

[33] G. Yu, F. Li, and Y. Yang, "Robust supply chain networks design and ambiguous risk preferences," International Journal of Production Research, vol. 55, no. 4, pp. 11681182, 2017/02/16 2017, doi: 10.1080/00207543.2016.1232499.

[34] C. Wang and Q. Hu, "Knowledge sharing in supply chain networks: Effects of collaborative innovation activities and capability on innovation performance," Technovation, 2017, doi: 10.1016/j.technovation.2017.12.002.

[35] J. Xu, Q. Liu, and R. Wang, "A class of multi-objective supply chain networks optimal model under random fuzzy environment and its application to the industry of Chinese liquor," Information Sciences, vol. 178, no. 8, pp. 2022-2043, 2008, doi: 10.1016/j.ins.2007.11.025.

[36] L. Ruiying, D. Qiang, J. Chong, and K. Rui, "A New Resilience Measure for Supply Chain Networks," Sustainability-Basel, vol. 9, no. 1, p. 144, 2017, doi: 10.3390/su9010144.

[37] H. Song, Q. Lu, K. Yu, and C. Qian, "How do knowledge spillover and access in supply chain network enhance SMEs' credit quality?," Industrial Management \& Data Systems, vol. 119, no. 2, pp. 274-291, 2019, doi: 10.1108/IMDS-01-2018-0049.

[38] Y. Ouyang and X. Li, "The bullwhip effect in supply chain networks," European Journal of Operational Research, vol. 201, no. 3, pp. 799-810, 2010, doi: 10.1016/j.ejor.2009.03.051.

[39] A. Nair, C. Blome, T. Y. Choi, and G. Lee, "Re-visiting collaborative behavior in supply networks - structural embeddedness and the influence of contextual changes and sanctions," Journal of Purchasing and Supply Management, vol. 24, no. 2, pp. 135-150, 2018/03/01/ 2018, doi: https://doi.org/10.1016/j.pursup.2017.11.006.

[40] P. Plapper, C. Oberhausen, and M. Minoufekr, "Application of value stream management to enhance product and information flows in supply chain networks Based on the example of web-based automotive retail business," Manag Prod Eng Rev, vol. 9, no. 2, pp. 13-19, 2018, doi: 10.24425/119521.

[41] D. J. Robb and E. A. Silver, "Erratum: Inventory management under date-terms supplier trade credit with stochastic demand and leadtime," J Oper Res Soc, vol. 57, no. 6, pp. 755-755, 2006/06/01 2006, doi: 10.1057/palgrave.jors.2602154.

[42] H. Pyo and S. Lee, "Are there spillover effects of large firms' growth in supply chain networks? Evidence from the Korean economy," Appl Econ Lett, vol. 25, no. 17, pp. 1208-1211, 2018, doi: 10.1080/13504851.2017.1412065.

[43] J. Pfeffer and G. R. Salancik, The external control of organizations: A resource dependence perspective. Stanford University Press, 2003.

[44] O. D. Palsule-Desai, D. Tirupati, and P. Chandra, "Stability issues in supply chain networks: Implications for coordination mechanisms," International Journal of 
Production Economics, vol. 142, no. 1, pp. 179-193, 2013, doi:

10.1016/j.ijpe.2012.11.003.

[45] Y. Wu, M. Dong, T. Fan, and S. Liu, "Performance evaluation of supply chain networks with assembly structure under system disruptions," Computers and Operations Research, vol. 39, no. 12, pp. 3229-3243, 2012, doi:

10.1016/j.cor.2012.04.006.

[46] K. E. Thuermer, "Machine learning is coming: artificial intelligence capabilities will help food companies make up-to-the-minute decisions that can reduce supply chain disruptions.(SECTOR REPORTS: SOFTWARE \& TECHNOLOGY)," Food Logistics, no. 182, p. 68, 2016.

[47] G. Baryannis, S. Validi, S. Dani, and G. Antoniou, "Supply chain risk management and artificial intelligence: state of the art and future research directions," International Journal of Production Research, vol. 57, no. 7, pp. 2179-2202, 2019/04/03 2019, doi: 10.1080/00207543.2018.1530476.

[48] W. I. Bullers, S. Y. Nof, and A. B. Whinston, "Artificial Intelligence in Manufacturing Planning and Control," A I I E Transactions, vol. 12, no. 4, pp. 351363, 1980/12/01 1980, doi: 10.1080/05695558008974527.

[49] A. Gunasekaran and E. W. T. Ngai, "Expert systems and artificial intelligence in the 21st century logistics and supply chain management," Expert Systems With Applications, vol. 41, no. 1, pp. 1-4, 2014, doi: 10.1016/j.eswa.2013.09.006.

[50] H. Min, "Artificial intelligence in supply chain management: theory and applications," International Journal of Logistics Research and Applications, vol. 13, no. 1, pp. 13-39, 2010, doi: 10.1080/13675560902736537.

[51] F. J. Martínez-López and J. Casillas, "Artificial intelligence-based systems applied in industrial marketing: An historical overview, current and future insights," Industrial Marketing Management, vol. 42, no. 4, pp. 489-495, 2013, doi:

10.1016/j.indmarman.2013.03.001.

[52] M.-H. Huang and R. T. Rust, "Artificial Intelligence in Service," J Serv Res-Us, vol. 21, no. 2, pp. 155-172, 2018, doi: 10.1177/1094670517752459.

[53] M. Klumpp, "Automation and artificial intelligence in business logistics systems: human reactions and collaboration requirements," International Journal of Logistics Research and Applications, vol. 21, no. 3, pp. 224-242, 2018/05/04 2018, doi: 10.1080/13675567.2017.1384451.

[54] J. Fan, L. Fang, J. Wu, Y. Guo, and Q. Dai, "From Brain Science to Artificial Intelligence," Engineering, vol. 6, no. 3, pp. 248-252, 2020/03/01/ 2020, doi: https://doi.org/10.1016/j.eng.2019.11.012.

[55] P. Radanliev et al., "Artificial intelligence and machine learning in dynamic cyber risk analytics at the edge," SN Applied Sciences, vol. 2, no. 11, p. 1773, 2020/10/06 2020, doi: 10.1007/s42452-020-03559-4.

[56] P. Radanliev, D. De Roure, M. Van Kleek, O. Santos, and U. Ani, "Artificial intelligence in cyber physical systems," AI \& SOCIETY, 2020/08/27 2020, doi: 10.1007/s00146-020-01049-0.

[57] W. S. McCulloch and W. Pitts, "A logical calculus of the ideas immanent in nervous activity," The bulletin of mathematical biophysics, vol. 5, no. 4, pp. 115-133, 1943.

[58] S. Russell and P. Norvig, "Learning in neural and belief networks," Artificial Intelligence: A Modern Approach. Upper Saddle River, NJ: Prentice-Hall, 1995.

[59] J. H. Park and S. C. Park, "Agent-based merchandise management in business-tobusiness electronic commerce," Decision Support Systems, vol. 35, no. 3, pp. 311333, 2003. 
[60] Z. Pawlak, "Rough set approach to knowledge-based decision support," European journal of operational research, vol. 99, no. 1, pp. 48-57, 1997.

[61] N. M. Sadeh, D. W. Hildum, D. Kjenstad, and A. Tseng, "MASCOT: an agent-based architecture for dynamic supply chain creation and coordination in the internet economy," Production Planning \& Control, vol. 12, no. 3, pp. 212-223, 2001.

[62] G. Satapathy, S. R. Kumara, and L. M. Moore, "Distributed intelligent architecture for logistics (DIAL)," Expert Systems with Applications, vol. 14, no. 4, pp. 409-424, 1998.

[63] G. F. Luger, Artificial intelligence: structures and strategies for complex problem solving. Pearson education, 2005.

[64] C. F. Cheung, W. M. Wang, V. Lo, and W. B. Lee, "An agent-oriented and knowledge-based system for strategic e-procurement," Expert Syst, vol. 21, no. 1, pp. 11-21, 2004.

[65] J. Liebowitz, Strategic intelligence : business intelligence, competitive intelligence, and knowledge management. Boca Raton, Fla.: Boca Raton, Fla. : Auerbach, 2006.

[66] J. Liebowitz, "Facilitating innovation through knowledge sharing: A look at the US Naval Surface Warfare Center-Carderock Division," (in English), J Comput Inform Syst, vol. 42, no. 5, pp. 1-6, 2002. [Online]. Available: <Go to ISI $>$ ://WOS:000177859500001.

[67] P. Humphreys, R. McIvor, and G. Huang, "An expert system for evaluating the make or buy decision," Comput Ind Eng, vol. 42, no. 2-4, pp. 567-585, 2002.

[68] F. Olan, J. Suklan, E. O. Arakpogun, and A. Robson, "Advancing Consumer Behavior: The Role of Artificial Intelligence Technologies and Knowledge Sharing," Ieee T Eng Manage, pp. 1-13, 2021, doi: 10.1109/TEM.2021.3083536.

[69] E. Mekov, M. Miravitlles, and R. Petkov, "Artificial intelligence and machine learning in respiratory medicine," Expert Review of Respiratory Medicine, pp. 1-6, 2020, doi: 10.1080/17476348.2020.1743181.

[70] F. Jia, C. Blome, H. Sun, Y. Yang, and B. Zhi, "Towards an integrated conceptual framework of supply chain finance: An information processing perspective," International Journal of Production Economics, vol. 219, pp. 18-30, 2020/01/01/ 2020, doi: https://doi.org/10.1016/j.ijpe.2019.05.013.

[71] R. Foresti, S. Rossi, M. Magnani, C. Guarino Lo Bianco, and N. Delmonte, "Smart Society and Artificial Intelligence: Big Data Scheduling and the Global Standard Method Applied to Smart Maintenance," Engineering, 2020/01/29/ 2020, doi: https://doi.org/10.1016/j.eng.2019.11.014.

[72] F. Caniato, M. Henke, and G. A. Zsidisin, "Supply chain finance: Historical foundations, current research, future developments," Journal of Purchasing and Supply Management, vol. 25, no. 2, pp. 99-104, 2019/03/01/ 2019, doi: https://doi.org/10.1016/j.pursup.2019.02.002.

[73] O. Oyemomi, S. Liu, I. Neaga, and A. Alkhuraiji, "How knowledge sharing and business process contribute to organizational performance: Using the fsQCA approach," Journal of Business Research, vol. 69, no. 11, pp. 5222-5227, 2016.

[74] B. Coulibaly, H. Sapriza, and A. Zlate, "Financial frictions, trade credit, and the 2008-09 global financial crisis," International Review of Economics \& Finance, vol. 26, pp. 25-38, 2013/04/01/ 2013, doi: https://doi.org/10.1016/j.iref.2012.08.006.

[75] K. J. Mizgier, S. M. Wagner, and J. A. Holyst, "Modeling defaults of companies in multi-stage supply chain networks," International Journal of Production Economics, vol. 135, no. 1, pp. 14-23, 2012, doi: 10.1016/j.ijpe.2010.09.022. 
[76] O. Oyemomi, S. Liu, I. Neaga, H. Chen, and F. Nakpodia, "How cultural impact on knowledge sharing contributes to organizational performance: Using the fsQCA approach," Journal of Business Research, vol. 94, pp. 313-319, 2019.

[77] M. Kotabe, X. Martin, and H. Domoto, "Gaining from vertical partnerships: knowledge transfer, relationship duration, and supplier performance improvement in the US and Japanese automotive industries," Strategic management journal, vol. 24, no. 4, pp. 293-316, 2003.

[78] H. Shin, D. A. Collier, and D. D. Wilson, "Supply management orientation and supplier/buyer performance," J Oper Manag, vol. 18, no. 3, pp. 317-333, 2000.

[79] L. Kave, "Common method biases in behavioral research: A critical review of the literature and recommended remedies," J Appl Psychol, vol. 88, no. 5, pp. 879-903, 2003.

[80] O. Oyemomi, S. Liu, and I. Neaga, "The contribution of knowledge sharing to organizational performance and decision making: A literature review," Decision support systems iv-information and knowledge management in decision processes, pp. $1-12,2014$.

[81] H. Chen, S. Liu, F. Oderanti, and O. Oyemomi, "Exploring the relationships between knowledge networks/mobilisation and lean performance in agri-food supply chain context: a fuzzy-set qualitative comparative analysis."

[82] J. A. Morente-Molinera, R. Wikstrom, E. Herrera-Viedma, and C. Carlsson, "A linguistic mobile Decision Support System based on fuzzy ontology to facilitate knowledge mobilization," (in English), Decision Support Systems, vol. 81, pp. 66-75, Jan 2016, doi: 10.1016/j.dss.2015.09.001.

[83] C. Ragin, "New Directions in the Logic of Social Inquiry," Polit Res Quart, vol. 66, no. 1, pp. 171-174, 2013.

[84] C. C. Ragin, "Qualitative comparative analysis using fuzzy sets (fsQCA)," Configurational comparative methods: Qualitative comparative analysis (QCA) and related techniques, vol. 51, pp. 87-121, 2009.

[85] C. C. Ragin and P. Pennings, "Fuzzy Sets and Social Research," Sociological Methods \& Research, vol. 33, no. 4, pp. 423-430, 2005, doi: $10.1177 / 0049124105274499$.

[86] A. K. Schmitt, A. Grawe, and A. G. Woodside, "Illustrating the Power of fsQCA in Explaining Paradoxical Consumer Environmental Orientations," Psychol Market, vol. 34, no. 3, pp. 323-334, 2017, doi: 10.1002/mar.20991.

[87] A. G. Woodside, "Moving beyond multiple regression analysis to algorithms: Calling for adoption of a paradigm shift from symmetric to asymmetric thinking in data analysis and crafting theory," Journal of Business Research, vol. 66, no. 4, 2013, doi: 10.1016/j.jbusres.2012.12.021.

[88] S. F. Wamba and M. M. Queiroz, "Blockchain in the operations and supply chain management: Benefits, challenges and future research opportunities," International Journal of Information Management, vol. 52, no. 2, p. 102064, 2020/06/01/ 2020, doi: 10.1016/j.ijinfomgt.2019.102064.

[89] J. Zhan, S. Li, and X. Chen, "The impact of financing mechanism on supply chain sustainability and efficiency," J Clean Prod, vol. 205, pp. 407-418, 2018/12/20/ 2018, doi: https://doi.org/10.1016/j.jclepro.2018.08.347.

[90] D. A. Wuttke, C. Blome, K. Foerstl, and M. Henke, "Managing the Innovation Adoption of Supply Chain Finance-Empirical Evidence From Six European Case Studies," J Bus Logist, vol. 34, no. 2, pp. 148-166, 2013, doi: 10.1111/jbl.12016. 


\section{Sustainable Supply Chain Finance and Supply Networks: The role of Artificial}

\section{Intelligence}

\section{Author information:}

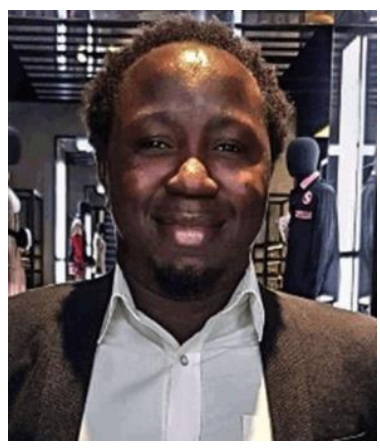

Femi Olan, $\mathrm{PhD}$ is a Senior Lecturer in Business Information Management at Northumbria University, UK. He obtained his PhD degree from Plymouth University, UK. He has teaching and industry experience in the field of information systems. His research interests focus on knowledge sharing, organisational factors, and performance management in organisations. He has collaborated on numerous research projects for, among others, development agencies. He has authored numerous articles in peer-reviewed journals and books.

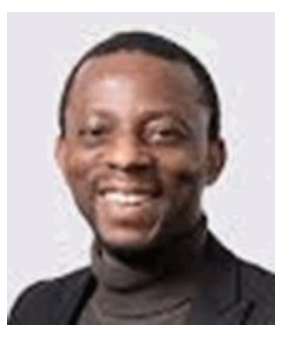

Emmanuel Ogiemwonyi Arakpogun, $\mathrm{PhD}$ is a Senior Lecturer in International Business Management at Newcastle Business School. His research interests lie at the nexus of the liberalisation of the telecommunications market and universal access policies as a combined strategy for closing the digital divides in emerging economies. He is a reviewer for Information Technology and People.

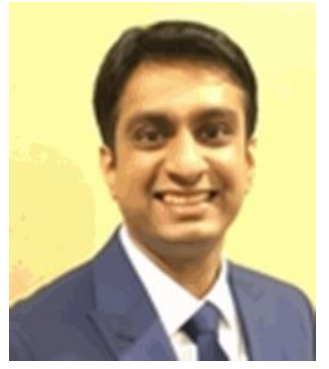

Uchitha Jayawickrama, $\mathrm{PhD}$ is a Lecturer in Information Systems (which is equivalent to Assistant Professor) at the Information Management Group, School of Business and Economics, Loughborough University, UK. He obtained his PhD degree from Plymouth University, UK. He has research, teaching, and industry experience in the field of information systems, particularly in the areas of enterprise systems, cloud ERP, business process automation, knowledge management, knowledge management systems, digitisation (digital innovation \& productivity), business intelligence, data analytics, and business process re-engineering. He 
has published research in various renowned conferences, books, and journals. He is involved in several research projects internally and externally. He is a reviewer for several journals and international conferences. He has editorial experience in various journals. He is a member of several scientific/technical/program committees.

Jana Suklan, $\mathrm{PhD}$ is an Associate Researcher at the Translational and Clinical Research

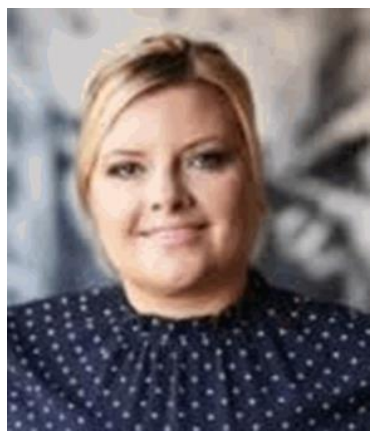
Institute at Newcastle University. She works across the University and National Institute for Health Research Newcastle In Vitro Diagnostics Co-operative. She holds a $\mathrm{PhD}$ in Interdisciplinary Statistics from the University of Ljubljana, Slovenia. Her thesis covered the application of econometric models for the analysis of synergetic effects within channels of integrated marketing communications. Her current work focuses on evaluations of novel medical devices from very early stages to adoption. She is professionally active in several research areas including social research, business and management, innovation, and healthcare.

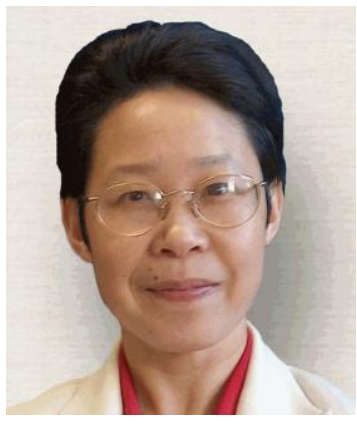

Shaofeng Liu, $\mathrm{PhD}$ is Professor of Operations Management and Decision-making. She obtained her Ph.D. degree from Loughborough University, UK. Her main research interests and expertise are in knowledge-based techniques to support business decision-making, particularly in the areas of knowledge management, integrated decision support, digital business, and quantitative decision methods. She is a senior editor for Cogent Business and Management, an open access journal. She has undertaken several influential research projects funded by UK research councils and the European Commission with a total value of over $€ 40$ million. She is currently the PI and Co-I for four EU projects under the Horizon 2020 programme. She has published over 150 peer-reviewed research papers. 